Hahitat Seguridad Socialo..

\title{
MURIENDO EN NUESTRO SISTEMA DE SALUD
}

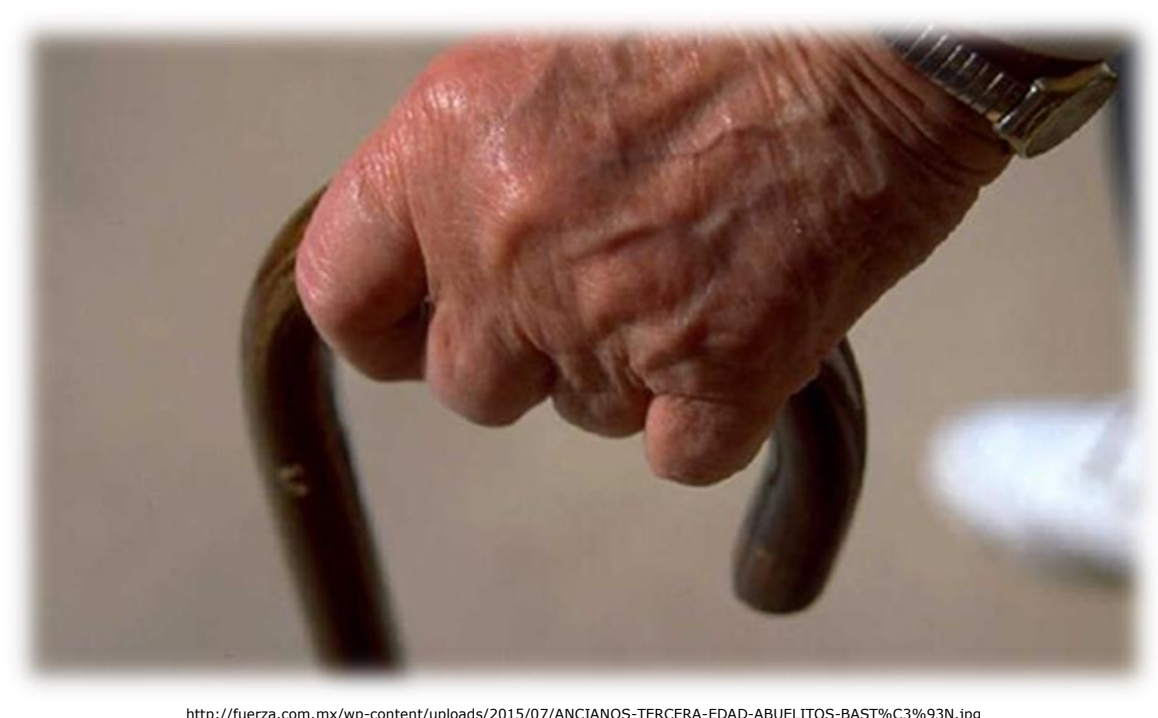

Día uno: Doña Emilia era una paciente de 93 años. Vivía en un hogar geriátrico en donde, luego de 10 años de cuidado, tras un sencillo tropezón cayó y se fracturó la cadera. Ella presenta un trastorno cognitivo de base y diagnosticado clínicamente.

En primera instancia se llamó a un servicio de atención domiciliaria de urgencias privado, el cual confirma la sospecha diagnóstica y al preguntar por la EPS a la que pertenece para verificar los probables sitios de traslado, se empiezan a mostrar renuentes a cumplir con su obligación, ya que a esa EPS ninguna clínica quiere atenderla pues les debe mucho dinero. Ellos (los del servicio privado de emergencia) saben que el traslado va ser un vía crucis pues saben que muchas clínicas a las que lleguen pueden rechazarlos y, por ende, perder todo el día trasladando a doña Emilia de un sitio a otro. Finalmente, y gracias a los vínculos de la hija (docente de una facultad de Medicina) de doña Emilia, deciden Ilevarla a un reconocido Hospital Universitario. Allí la dejan en urgencias donde recibe la primera atención y de una vez le confirman que deberá ser remitida pues en el momento no tienen contrato con esa EPS.

Día dos: Deciden pedirle un TAC para descartar lesión neurológica el cual se lo hacen en las horas de la madrugada en otro sitio, trasladándola y volviéndolo a traer. La hija sostiene que por ello se resfrió. En urgencias le confirman a la hija de doña Emilia que debe ser operada de la 
cadera, pero que será remitida a otra clínica, esto a pesar de que dicho hospital cuenta con un reconocido equipo para atender el caso. Doña Emilia, por su condición mental, está desorientada. Su contacto con la hija se intensifica y, evidentemente, se calma al estar al lado de ella.

Día tres: Salvo un resfriado, doña Emilia permanece sin cambios. Esta más desorientada pues no reconoce muy bien lo que está pasando. La hija averigua por la reputación de la clínica a donde será remitida, encontrando que es un sitio en donde se han presentado numerosas quejas. Por tal motivo decide pedir que no la trasladen y que la operen allí. Invoca la Política de Atención Integral. El hospital dice que nada puede hacer.

Día cuatro: Doña Emilia está presentando síntomas respiratorios más marcados. La hija decide hacer valer lo que considera los derechos de su madre, razón por la cual acude a la Defensoría del Pueblo, donde luego de exponer su caso le dan un oficio con el cual acude al hospital. Pide ser atendida en el hospital donde se encuentran.

Día cinco: La hija, gracias algunas conexiones con antiguos alumnos, ha ganado simpatía por su causa. El hospital reenvía a la EPS el oficio y finalmente la EPS decide autorizar el manejo en el hospital. La hija refiere que no ha tenido un contacto "sólido" con los médicos, salvo con dos internos que han estado particularmente atentos. Es visitada por un cirujano, quien le dice que la van a operar siempre y cuando las interconsultas salgan bien.

Día seis: La cirugía es pospuesta debido a que doña Emilia está haciendo un cuadro respiratorio. La hija expresa mucha angustia pues ve que su madre se está deteriorando. Ella y su hija (nieta de doña Emilia) pueden estar constantemente con ella.

Día siete: Doña Emilia se ha complicado desde el punto de vista respiratorio. Un médico que la valora habla de la necesidad de intubarla. La hija no lo permite pues esa fue una solicitud previa de su madre. Doña Emilia fallece abrazada por su hija y por su nieta. Fue acompañada por uno de los internos.

\section{Comentario}

\section{$\overline{\text { EL ESPECTADOR }}$ \\ SÁBADO, 16 DE JUL DE 2016 Última Actualización: 12:39 pm}

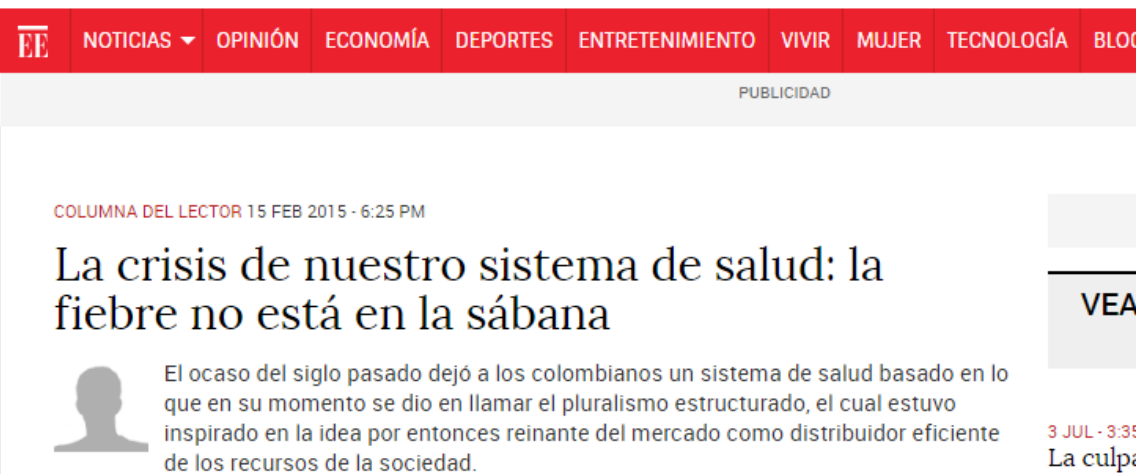


El caso de doña Emilia es un triste y dramático ejemplo de la situación que hoy vivimos en nuestro crítico sistema de salud (1). Pone de manifiesto muchos aspectos que vale la pena resaltar, pretendiendo que todos creemos una conciencia para impulsar la necesaria trasformación de los maltrechos servicios de salud (2). Buscando una tipología que nos permita entender, se propone usar la Ley Estatutaria (3) como marco de análisis. Al respecto:

\section{Artículo 2. Naturaleza y contenido del derecho fundamental}

Dice la Ley que el acceso a los servicios de salud debe ser oportuno y con calidad. En el caso de doña Emilia, pudo acceder, pero de una forma tórpida, llena de obstáculos. ¿Por qué? Sencillamente porque la mayoría de los prestadores a la EPS a la que pertenece no le quieren prestar servicio.

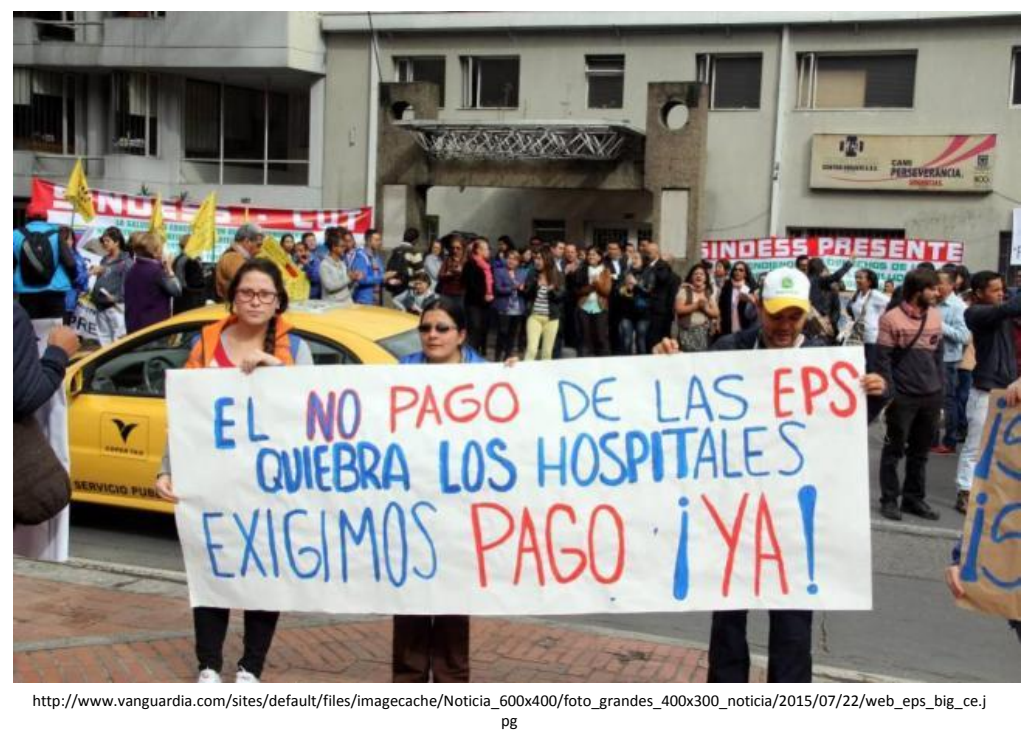

¿Por qué? Pues porque las EPS no pagan y sin reparo son capaces de "quebrar" a las clínicas y hospitales al no responder por los costos de las atenciones (4).

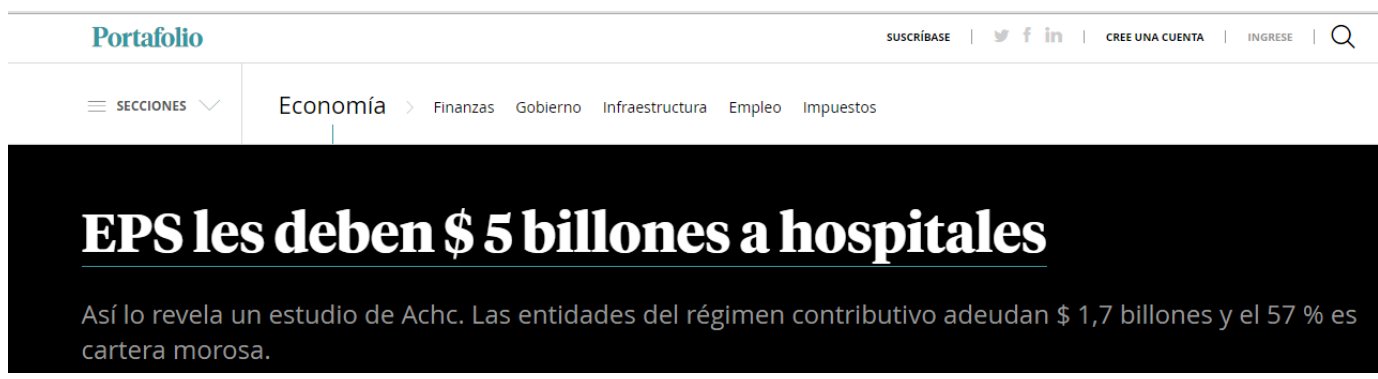




\section{Dice el artículo 5: El Estado es responsable de proteger y garantizar el goce efectivo...}

No se cumple. A doña Emilia no la defendió el Estado. Ciertamente se debe reconocer que la Defensoría sirvió. Pero fueron las acciones de la hija las responsables de que no la trasladaran de un sitio con la capacidad para atenderla a otro de dudosa reputación (donde la prestación está sujeta a las órdenes de la EPS) (5). En Colombia se ha demostrado que no es a través de leyes, decretos, resoluciones que se protege a la población. Solo la tutela (6) de los dolientes ha demostrado algún grado de utilidad.

\section{Artículo $6^{\circ}$. Elementos y principios del derecho fundamental de la salud}

La información que obtuvo la hija de doña Emilia acerca del sitio donde la pensaban remitir fue negativa. La Ley Estatutaria establece la necesidad de ofrecer un servicio de calidad e idoneidad profesional. De esto surge la pregunta: ¿Existen IPS donde se pone en riesgo la vida de los pacientes?

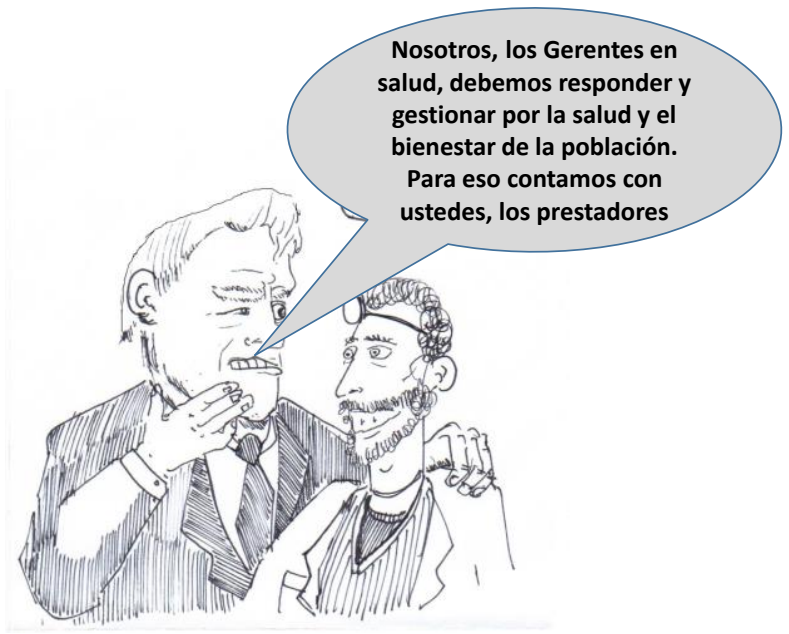

No me atrevo a contestar dado que asumo que el sistema de habilitación tendrá esto en vigilancia. Lo que intuyo que debe ser el criterio, es la existencia de un sistema de vigilancia de mortalidad, a través del cual se pueda estar verificando de qué y cuántos pacientes fallecen en cada IPS y con eso sacar indicadores esperados. Lo propio será de pacientes intervenidos, hospitalizados, donde se describan los comportamientos, se comparen entre IPS similares y de ahí se obtengan los indicadores esperados.

\section{El asunto en el caso de doña Emilia}

La hija de doña Emilia debería haber tenido, casi desde que sucedió el evento, el conocimiento de las redes de prestación de la EPS (7) para este caso. Creería que, idealmente, ella debería haber tenido un número telefónico al cual llamar para conocer el sitio donde la referirían para ser atendida. En esa red de servicios deberían estar referenciados los sitios con los mejores indicadores. Pero la realidad es que algunas EPS sí tienen una preferencia para las IPS: Ios que forman parte de su red (8) (así la ley diga que no) o aquellos que cobran menos. ¿Es malo que las EPS tengan su propia red? Eso se llama la integración vertical y se ha demostrado que tal modelo, cuando las EPS buscan rentabilidad 
económica, hace que las IPS de su red busquen principalmente dejar esa rentabilidad, esto anteponiéndose a lo que debería ser su misión fundamental como es la atención en salud de la más alta calidad de la población que atienden. ¿Cómo lo hacen las IPS? Recibiendo todo lo que puedan (incluso lo que no pueden) y contratando a los prestadores en condiciones precarias laboralmente. En contra de esto es que la Ley 100 propuso entre sus principios la autonomía administrativa de las EPS y de las IPS. Pienso que existe suficiente evidencia de que la integración vertical en nuestro sistema de salud no ha demostrado ser una ventaja... Más bien, es una desventaja para los pacientes.

\section{Lo cierto}

Digo, de forma hipotética, que muy pocas EPS presentan a sus usuarios las IPS que tienen los mejores indicadores en torno a la atención en salud. iNo es la salud o el bienestar el criterio de selección! Esto es una clara violación a la Ley Estatutaria.

\section{El ideal}

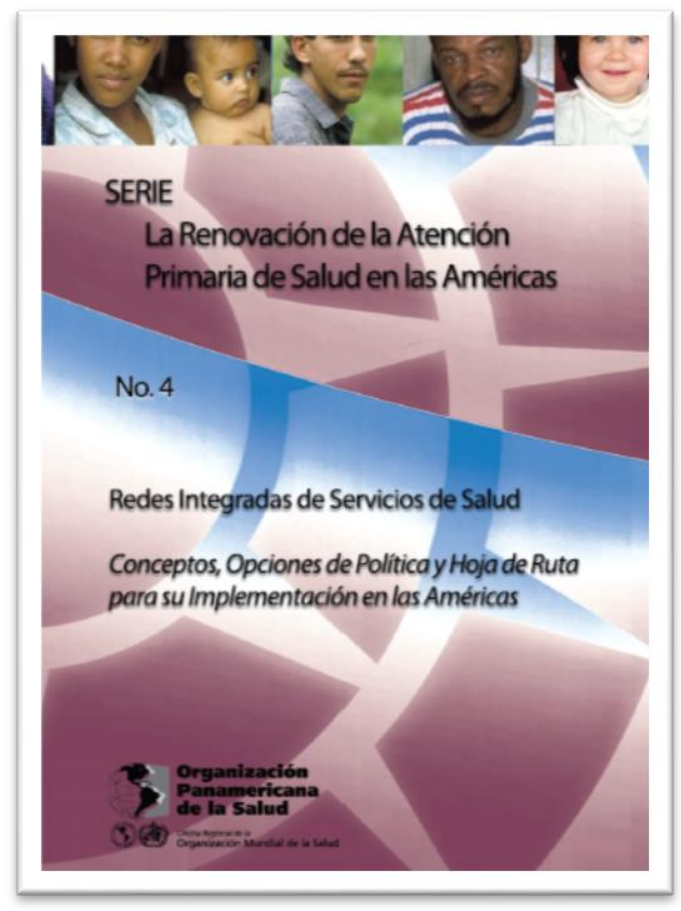

Las EPS deberían pagar por la prestación a todas las IPS lo mismo (de acuerdo a lo que ofrezcan). Cobrar menos por parte de las IPS, no puede ser un criterio para contratarlas. El criterio debe ser la mejor atención posible medida en correspondencia. En el caso de doña Emilia, la EPS debe pagar por la atención lo mismo en cualquier IPS con la capacidad, y sus preferencias de contratación estarán por la que ofrezca los mejores resultados. iEso lo deben conocer los usuarios! 


\section{Lo real}

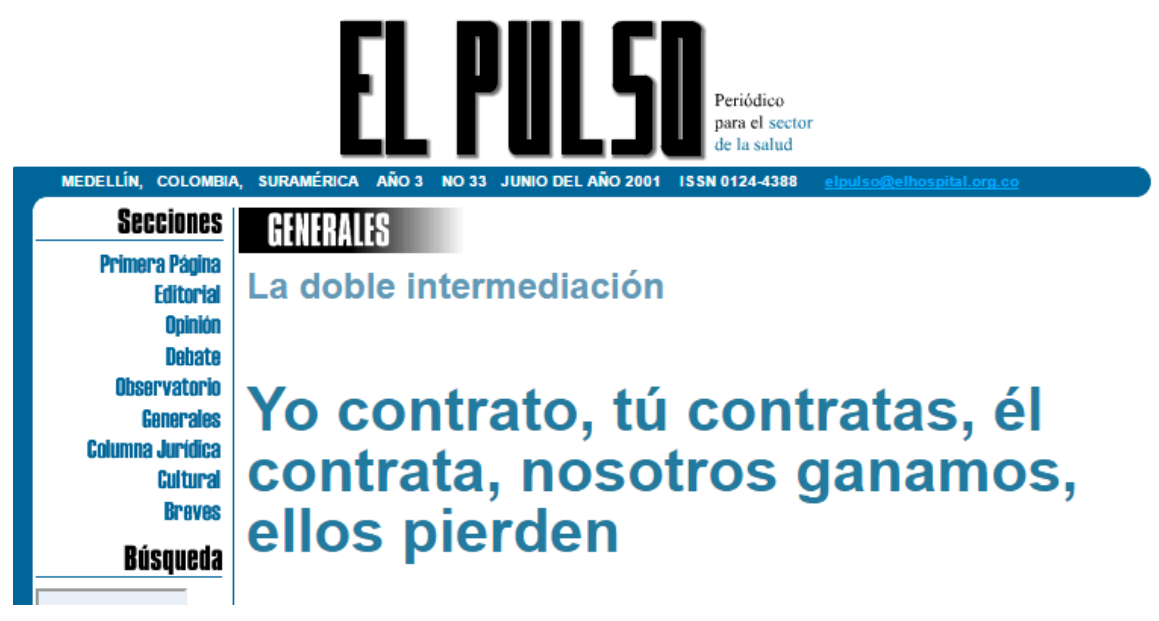

Lo que hoy vemos son unos contratos perversos, donde las EPS usando "su población" contratan en condiciones desventajosas y las IPS a su vez replican esa perversión en sus prestadores (9). ¿Por qué no cobrar lo que es? ¿Acaso hoy no podemos calcular cuánto va a durar un paciente hospitalizado? ¿Acaso no podemos calcular cuánto va a gastar? Si podemos calcularlo, lo obvio es pagarle justo eso... Se puede usar el promedio obtenido de las distintas prestaciones, con un margen. Pagar menos es arriesgar a los pacientes a que no les den la atención que necesitan.

\section{Otra violación}

Lo anterior pone de manifiesto una violación más a la Ley Estatutaria en lo que plantea en el artículo 6 (Elementos y principios del derecho fundamental a la salud.) acerca de la libre elección. No existe la libre elección si no nos dan elementos para escoger. Los pacientes (hoy usuarios) deben tener acceso a la información que le muestre las IPS donde se obtienen los mejores resultados en salud ¿no es lo obvio?

\section{Artículo 15. Prestación de servicios de salud}

¿Cuál hubiera sido la mejor atención para doña Emilia? El desenlace ocurrido nos hace pensar que no recibió la mejor atención. Sin embargo, doña Emilia era una paciente de 93 años con un altísimo riesgo de fallecer per se. Probablemente la pregunta es si la cirugía es la mejor opción o un manejo expectante. No dudo de que la respuesta está en la búsqueda de la evidencia, la cual, por cierto, una vez obtenida con sus posibilidades, se deberá ofrecer a la hija, quien, en últimas, será la que debe escoger. La hija se lamentó de que nunca fue abordada por un médico al cual ella pudiera identificar como el que tenía el manejo de su mamá y con quien pudiera hablar. Tan solo un par de internos la acompañaron, ¿será porque así se los enseñaron o porque ya la conocían y ese trato fue una excepción? Esas relaciones humanas de los médicos en torno a sus pacientes y los familiares no se deben descuidar (10). No en vano, muchas veces sabemos que los pacientes que atendemos van a fallecer y lo único que nos piden es que los acompañemos. 


\section{Una decisión: morir dignamente (11)}

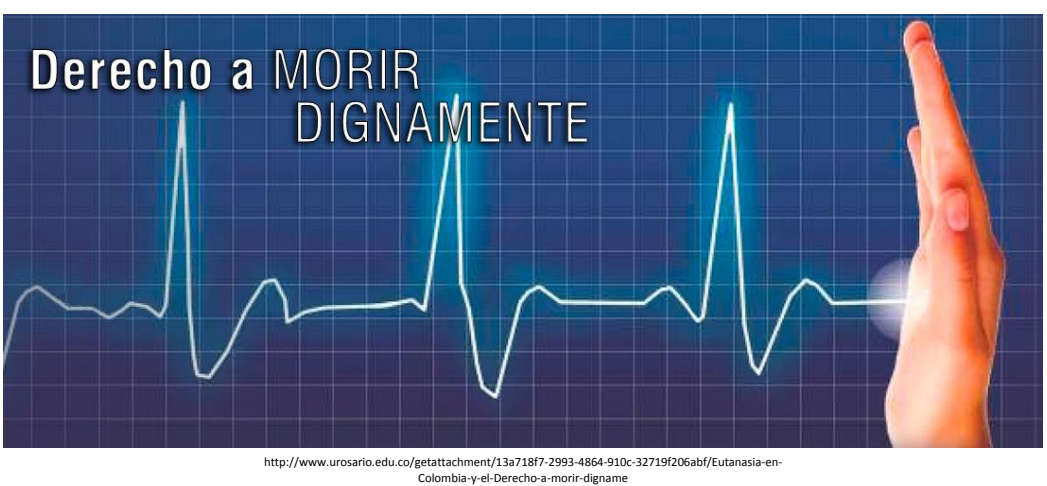

Se trata de un movimiento que cada día, y en la medida que vivimos más, los pacientes quieren hacer uso. Curiosamente los médicos no lo abordamos con la frecuencia necesaria. Doña Emilia y su hija lo tenían claro... No manejos extraordinarios. Mi madre, y algunos de los pacientes que he visto en servicios hospitalarios, al abordar el tema, así lo han decidido: no quieren entrar a una unidad de cuidados intensivos. Prefieren que les permitan el desenlace mortal en una hospitalización, si ese fuese el caso.

\section{Es su derecho...}

No es justo que las IPS no quieran atender a la EPS. El caso de doña Emilia pone esto de manifiesto. ¿Por qué están quebradas muchas de las EPS? (12) ¿Por qué unas lo están y otras no?

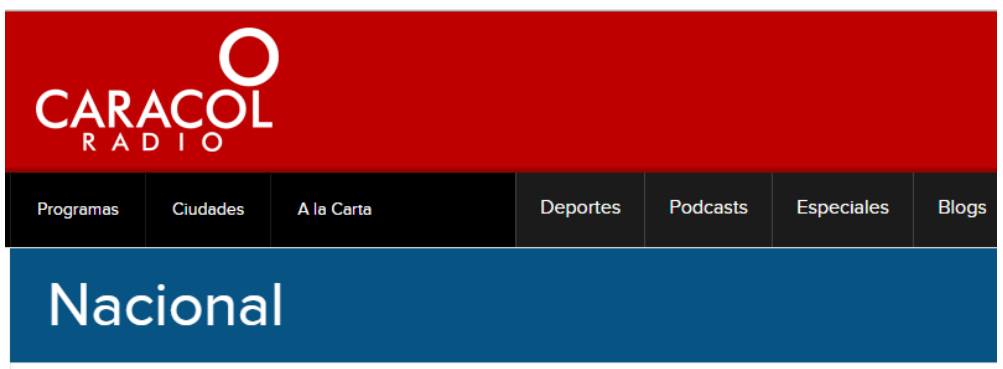

\section{Nuevo Ranking de las EPS revela su crítica situación financiera}

El $67 \%$ de las EPS del régimen subsidiado no pasaron evaluación, mientras que el $31 \%$ del contributivo no lo hicieron

La respuesta que yo doy es por corrupción. Es por malversación de recursos, es por usar un dinero destinado para la salud en "otros" negocios que, a la postre, se quiebran y hacen perder los recursos (13). Esto determina que muchas EPS usen el recaudo en pagar sus "negocios" (más en el pasado) y no lo en lo que deberían, como es el POS (Plan Obligatorio de Salud) a las IPS que se lo prestan. Hoy, 
tal vez, el riesgo está en que por estar en situación financiera incierta, el pago a las IPS que les prestan es aún más inseguro (14). Si bien acá se puede censurar esa inclusión del estímulo perverso a la ganancia privada, lo grave es que cuando el Estado ha intervenido no solo no impulsó la corrección de los problemas, sino que entregó a la politiquería corrupta las entidades, aumentando el daño, la defraudación y, en consecuencia, deteriorando la salud de gran parte de los colombianos (15).

El recaudo de la salud son dineros públicos de destinación específica y no se deben usar en nada distinto. Esta es la sentencia que aclaró la Corte Constitucional (16).

\section{Un camino}

Yo creería que el manejo de doña Emilia hubiese podido ser como sigue:

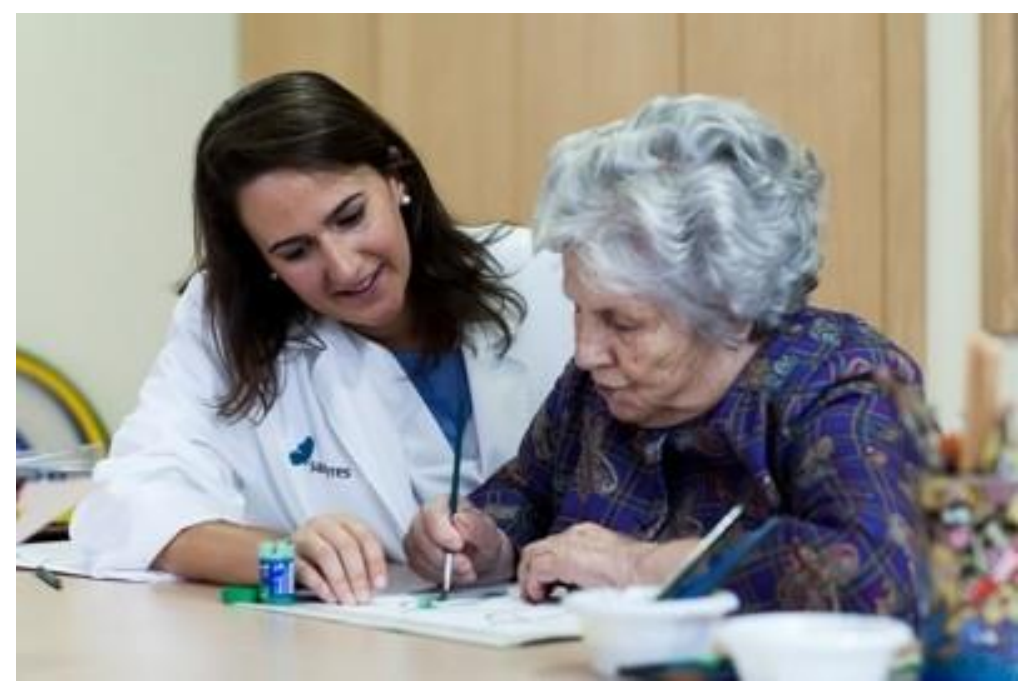

http://www.plusesmas.com/pictures/articulos/2000/2906.jpg

1. El hogar geriátrico donde ella está, es visitado regularmente por un equipo de Atención Primara en Salud (17).

1.1. Dicho equipo ya conoce a doña Emilia. Tienen su historia clínica. Le dan apoyo en su trastorno cognitivo. Conocen a la hija y han elaborado un plan en conjunto entre el hogar, la hija y el equipo de APS. Han evaluado e identificado los riesgos existentes en el hogar geriátrico, entre ellos los de caídas. Lo tienen medido en tal sentido y saben que el personal del hogar hace lo posible por prevenir tal evento. Pero saben que es inevitable que se presenten casos. El equipo y la hija se conocen. Han hablado de qué deben hacer en caso de que se presenten situaciones extremas de salud. 
Rutas integrales: objetivo...iVencer la fragmentación!

\section{GUIAS}

Plan de intervenciones colectivas
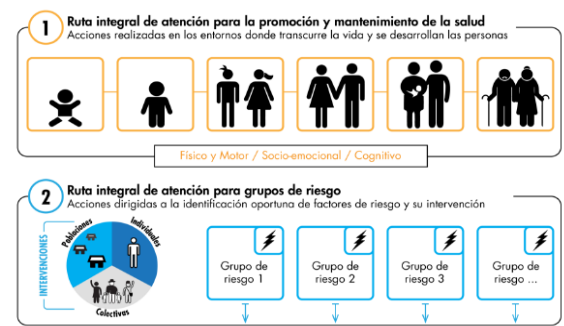

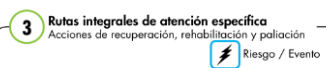

TOMA DE DECISIONES

Plan de beneficios

Responsables de la Intęegrallidad

1.2. El equipo de salud, junto con los prestadores del hogar geriátrico, tienen una ruta seleccionada (18) para las entidades y condiciones que se presentan con más frecuencia en este grupo de edad, información que se tiene de las prevalencias nacionales y las propias del hogar. Allí está descrita la ruta a seguir por una fractura de cadera. La hija como responsable de su mamá, la conoce.

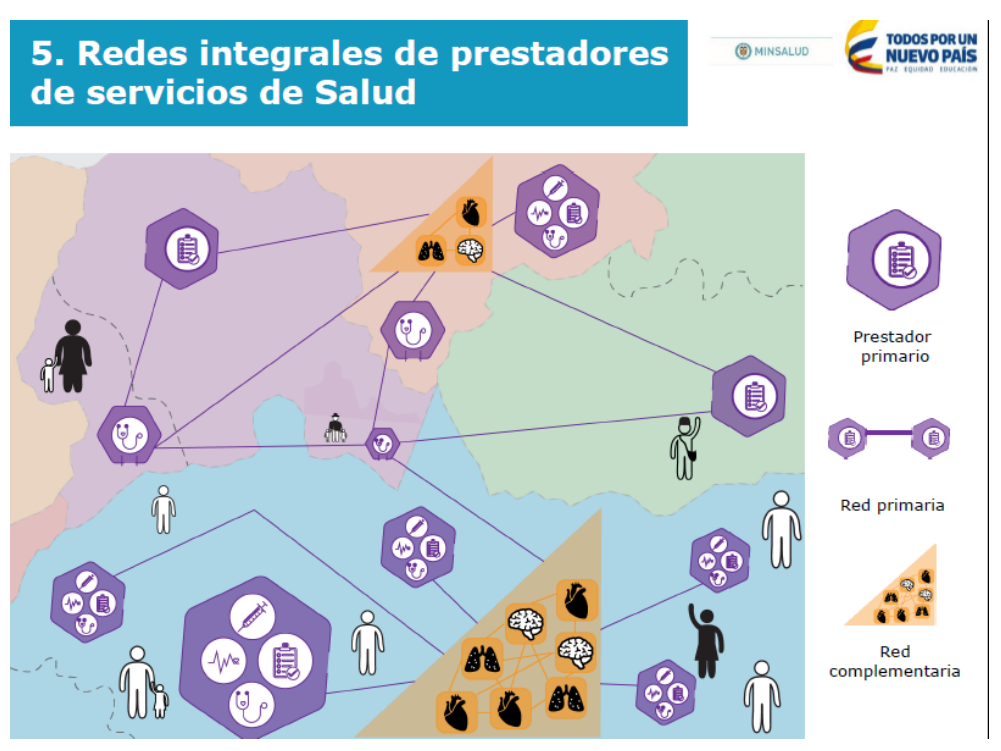

1.3. Una vez ocurrido el percance, el hogar sabe cuál es la IPS de referencia (está en la ruta). El servicio en ambulancia no es privado, es público y doña Emilia es trasladada sin inconveniente. Al llegar a la IPS, allí pueden acceder a la historia clínica que el equipo primario de atención hizo de doña Emilia en el hogar geriátrico. 
1.4. En urgencias de la IPS doña Emilia es atendida y la conducta a seguir es definida en las primeras tres horas. Allí, basados en la evidencia (19), le ofrecen a la hija las opciones. La IPS conoce un promedio del costo de la atención de doña Emilia y sabe que no tendrá conflicto con la EPS (pues pertenece a una red y están de acuerdo en los valores).

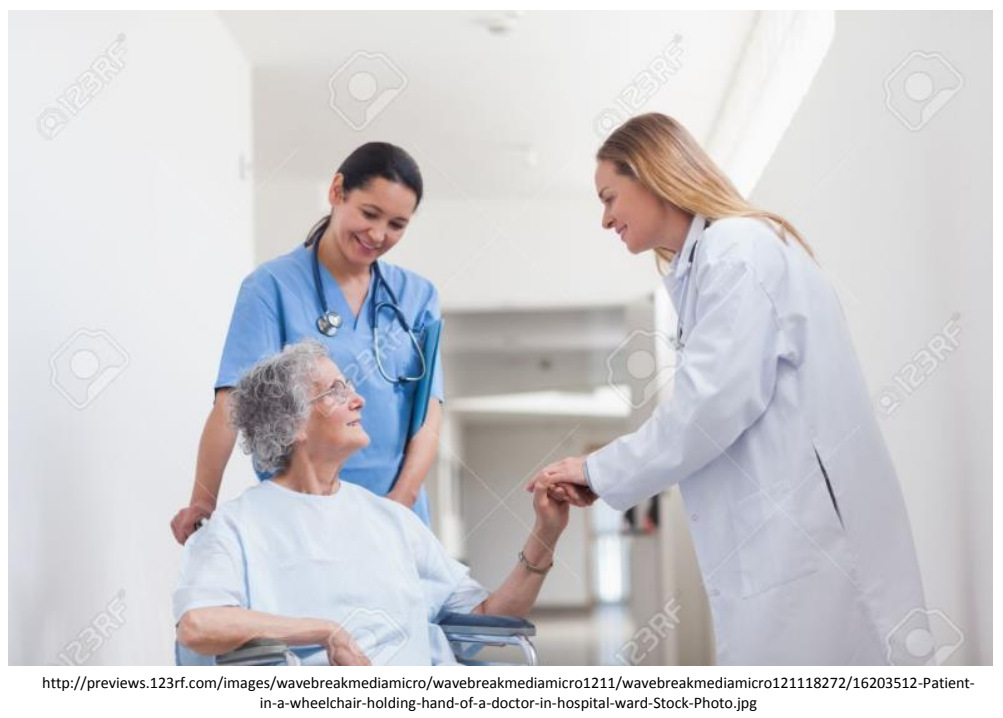

1.5. Un médico (familiar u hospitalario) se pone al servicio de la hija de doña Emilia y le dice que él será el encargado de la atención integral durante la hospitalización. Le presenta asimismo a los internos que lo ayudarán y que, junto con él, estarán atentos a las dudas que surjan.

1.6. La IPS tiene unas instalaciones dignas y le recomiendan que la hija o algún otro familiar acompañen en el cuarto a doña Emilia, de ser posible de forma permanente.

1.7. Es atendida siempre con una comunicación entre la hija y el médico responsable de la atención de doña Emilia.

1.8. El equipo médico a cargo, luego de analizar el caso, decide seguir un determinado procedimiento que explica a la hija. Ella lo acepta.

1.9. Doña Emilia se complica. Atendiendo la posición de doña Emilia y su hija, no se le practican maniobras extraordinarias y doña Emilia fallece.

1.10. La EPS Ilama a la hija; le dan su sentido pésame y le preguntan cómo fue la atención hacia doña Emilia.

¿Será que una atención así es posible?

Bueno, pues eso es lo que interpretamos que propone la Política de Atención Integral (20), pero para hacerla real, para hacerla posible, debemos unirnos y cambiar este maltrecho y corrupto sistema de salud y promover y luchar por convencernos de que es posible un sistema donde la salud no sea negocio... iSea un derecho! 


\section{REFERENCIAS}

(1) Columna del lector. La crisis de nuestro sistema de salud: la fiebre no está en la sábana. [Internet]. El Espectador [15 Feb 2015]. Disponible en: http://www.elespectador.com/lectores/crisis-de-nuestro-sistema-de-salud-fiebre-no-estasaban-columna-544258

(2) $1^{\circ}$ Parte: ACHC en debate sobre crisis del sistema de salud en Semana en vivo [video en Internet]. https://www. youtube.com/watch?v=GvRn_YH1VtY

(3) Alcaldía Mayor de Bogotá [Internet]. Ley estatutaria de salud del 2015. [aprox. 12 pantallas]. Disponible en: http://www.alcaldiabogota.gov.co/sisjur/normas/Norma1.jsp?i=60733

(4) Portafolio [Internet]. EPS les deben $\$ 5$ billones a hospitales. [11 Jul 2014]. Disponible en: http://www.portafolio.co/economia/finanzas/eps-les-deben-billones-hospitales-61318

(5) Semana [Internet]. Así controlan las instituciones y empresas de salud a los médicos. [25 Nov 2014]. Disponible en: http://www.semana.com/nacion/articulo/las-eps-controlan-los-medicos-con-polemicos-metodos/409528-3

(6) Noticias RCN [Internet]. Tutelas interpuestas para asuntos de salud han aumentado en Colombia [25 Feb 2015]. Disponible en: http://www.noticiasrcn.com/nacional-pais/tutelas-interpuestas-asuntos-salud-ha-aumentado-colombia

(7) Supersalud [Internet]. Rede de Prestación de Servicios de las EPS del Régimen Contributivo [actualizado 1 Ago 2014]. Disponible en: https://www.supersalud.gov.co/es-co/delegadas/supervision-institucional/base-de-datos-vigilados/redde-prestaci\%C3\%B3n-de-servicios-de-las-eps/red-de-prestaci\%C3\%B3n-de-servicios-de-las-eps-del-r\%C3\%A9gimencontributivo

(8) Parra LF. ¿Qué es la Integración Vertical en Salud? Negocio antes que mejoras [Internet 17 Oct 2013]. Disponible en: http://lasillavacia.com/elblogueo/blog/que-es-la-integracion-vertical-en-salud-negocio-antes-que-mejoras

(9) Muñoz OL. Yo contrato, tú contratas, él contrata, nosotros ganamos, ellos pierden. [Inernet]. El Pulso [Año 3 No 33 Jun 2001]. Disponible en: http://www.periodicoelpulso.com/html/jun01/general/general-09.htm

(10) González JC, Restrepo GL, Hernández AD, Ternera DC, Galvis CA, Pinzón JA. Satisfacción de pacientes que acudieron al primer nivel de atención en Bogotá. Rev. salud pública [Internet]. 2014; 16(6): 871-884 [citado 18 Jul 2016 ]. Disponible en: http://www.scielosp.org/scielo.php?script=sci_arttext\&pid=S0124-00642014000600006\&lng=en

(11) Orozco C. Muerte digna: la otra cara del derecho a la vida: Jaime Arrubla [Internet]. El Espectador [4 Jul 2015]. Disponible en: http://www.elespectador.com/entrevista-de-cecilia-orozco/muerte-digna-otra-cara-del-derecho-vidajaime-arrubla-articulo-570232

(12) Caracol Radio [Internet]. Nuevo Ranking de las EPS revela su crítica situación financiera [10 Ene 2014]. Disponible en: http://caracol.com.co/radio/2014/01/10/nacional/1389348060_052410.html

(13) Portafolio [Internet]. Imputan cargos a responsables de dineros en Saludcoop [7 Nov 2012]. Disponible en: http://www.portafolio.co/negocios/empresas/imputan-cargos-responsables-dineros-saludcoop-103116

(14) Contraloría General de la República [Internet]. Seguimiento a las fuentes y usos de los recursos del sector salud Informe No. 9 Junio de 2013 en Colombia. Disponible en: http://www.contraloria.gov.co/documents/155638087/171664330/Informe Salud_09-Final.pdf/e1903a2f-7f25-4af28cd4-e50a021573f2?version $=1.2$

(15) Caracol Radio [Internet]. Supersalud admite que hubo segundo saqueo de Saludcoop [4 Mar 2016]. Disponible en: http://caracol.com.co/programa/2016/03/04/6am_hoy_por_hoy/1457094537_541140.html

(16) Corte Constitucional [Internet]. Sentencia C-262/13 diciembre del 2010. Disponible en: http://www.corteconstitucional.gov.co/RELATORIA/2013/C-262-13.htm

(17) Ministerio de Salud y Protección Social [Internet]. Sistemas de salud basados en la Atención Primaria de Salud: Estrategias para el desarrollo de los equipos de APS. Washington, D.C. OPS, 2008. Disponible en: https://www.minsalud.gov.co/Documentos\%20y\%20Publicaciones/ESTRATEGIAS\%20PARA\%20EL\%20DSARROLLO\%20 DE\%20LOS\%20EQUIPOS\%20DE\%20SALUD\%20APS.pdf

(18) OPS. Redes integradas de servicios de salud. [Internet]. Serie La Renovación de la Atención Primaria en las Américas. N04. Disponible en: http://www.paho.org/uru/index.php?option=com_docman\&task=doc_view\&gid=145\&Itemid=250

(19) Grigoryan KV, Javedan H, Rudolph JL. Ortho-Geriatric Care Models and Outcomes in Hip Fracture Patients: A Systematic Review and Meta-Analysis.Journal of orthopaedic trauma. 2014; 28(3):e49-e55.

(20) Ministerio de Salud y Protección Social [Internet]. Política Integral de Atención de Salud. Disponible en: https://www.minsalud.gov.co/Paginas/politica-integral-de-atencion-en-salud.aspx 